\title{
Tempora mutantur...
}

Im Gesundheitswesen ist derzeit vieles im Umbruch, auch der Arztberuf ist einem zunehmenden Wandel unterzogen; waren finanzielle Mittel vor einigen Jahren noch mehr oder weniger uneingeschränkt vorhanden, zwingt uns die zunehmende Mittelknappheit seit einiger Zeit zu Diskussionen über Themen wie etwa die Zahl der Leistungserbringer; damit verbunden die Diskussionen rund um den Zulassungsstopp oder die drohende Aufhebung des Kontrahierungszwangs.

Ein Wandel des Arztbildes ist ebenfalls unverkennbar. War früher der Werdegang in etwa vorgegeben (Studium, einige Jahre Weiterbildung und Oberarzttätigkeit, dann der Übertritt in die Praxis und damit selbständige Tätigkeit oder akademische Laufbahn), zeichnet sich immer mehr eine Trendwende ab: infolge schlechterer Perspektiven hat u. a. der Drang in die Praxis nachgelassen und dürfte auch in $\mathrm{Zu}$ kunft noch weiter abnehmen. Diese Entwicklung führt dazu, dass Ärztinnen und Ärzte nach Abschluss ihrer Weiterbildung tendenziell länger an Spitälern tätig bleiben. Neue ärztliche Betätigungsfelder eröffnen sich in steigendem Ausmass in verschiedenen (nicht nur medizinischen) Bereichen.

Mag einiges im Umbruch sein, und verfolgen die verschiedenen Ärztegruppierungen z. T. unterschiedliche Interessen, dürfen wir alle eines nie aus den Augen verlieren: unsere Patientinnen und Patienten, um deren Wohl es uns letztlich geht.
Die Beziehung «Arzt-Patient» hat sich im Verlaufe der Zeit ebenfalls geändert.

Wo früher der Arzt als Halbgott in Weiss und noch früher als privilegierter «Heiler oder Medizinmann» angesehen wurde, unnahbar, unfehlbar und allwissend, sind in der heutigen Zeit Arzt und Patient eher ein Team. Ein Team, das gemeinsam den besten Weg im Bekämpfen einer Krankheit oder einer Befindlichkeitsstörung sucht.

In der Regel nimmt der Arzt in diesem Team verschiedene Aufgaben wahr. Er ist Experte in Gesundheitsfragen aller Art, Vertrauensperson, Vermittler gegenüber Versicherern, manchmal auch Angehörigen, dem Arbeitgeber und eventuell noch weiteren.

Patienten haben nicht selten eine diskrepante Auffassung zwischen «den Ärzten» und dem eigenen Arzt. Betrachten sie (wohl u. a. auch aufgrund reisserischer Presseberichte) «die Ärzteschaft» manchmal mit Skepsis oder Argwohn, steht der eigene Arzt meist in der Gunst der Betreffenden.

Tempora mutantur ...; das Kernanliegen der Ärzteschaft, nämlich das Wohl der Patientinnen und Patienten, bleibt jedoch dasselbe.

Susanna Stöhr, Mitglied des Zentralvorstandes 